University of Wollongong

Research Online

Faculty of Business - Papers (Archive)

Faculty of Business and Law

$1-1-2015$

The role of resident perceptions in achieving effective community-based tourism for least developed countries

Sotear Ellis

Edith Cowan University

Lynnaire Sheridan

University of Wollongong, lynnaire.sheridan@otago.ac.nz

Follow this and additional works at: https://ro.uow.edu.au/buspapers

Part of the Business Commons

Research Online is the open access institutional repository for the University of Wollongong. For further information contact the UOW Library: research-pubs@uow.edu.au 


\title{
The role of resident perceptions in achieving effective community-based tourism for least developed countries
}

\author{
Abstract \\ Community-based tourism (CBT) can be a tool for sustainable development in least developed countries; \\ however, careful selection of participating communities is vital to achieving development outcomes. This \\ article presents resident perceptions of self and the community (and its tourism organizers) as potential \\ indicators for future CBT success both contributing to theoretical concepts but pragmatically potentially \\ also assists practitioners to identify communities that theoretically should produce better development \\ outcomes before embarking on projects.

\section{Keywords} \\ developed, tourism, countries, role, resident, perceptions, achieving, least, effective, community \\ Disciplines \\ Business

\section{Publication Details} \\ Ellis, S. \& Sheridan, L. (2015). The role of resident perceptions in achieving effective community-based \\ tourism for least developed countries. Anatolia: an international journal of tourism and hospitality \\ research, 26 (2), 244-257.
}


The role of resident perceptions in achieving effective Community Based Tourism for Least Developed Countries

Sotear Ellis and Lynnaire Sheridan ${ }^{1}$

Faculty of Business, University of Wollongong, Wollongong, Australia

Sotear Ellis, 14 Tambelyn Street, Clarkson, WA 6030, Australia; email:

sotearellis@hotmail.com

1. School of Management and Marketing, Faculty of Business, University of

Wollongong, Wollongong NSW 2522, Australia. Email: Lynnaire@uow.edu.au 


\title{
The role of resident perceptions in striving for effective Community Based Tourism for Least Developed Countries
}

\author{
Community Based Tourism can be a tool for sustainable development in Least \\ Developed Countries, however, careful selection of participating communities is \\ vital to achieving development outcomes. This paper presents resident \\ perceptions of self and the community (and its tourism organisers) as potential \\ indicators for future Community Based Tourism success both contributing to \\ theoretical concepts but pragmatically potentially also assists practitioners to \\ identify communities that theoretically should produce better development \\ outcomes before embarking on projects.
}

Keywords: community based tourism; least developed countries; tourism indicators; resident perceptions; Cambodia

\section{Introduction}

In the twenty first century, tourism has emerged as a vehicle for community development in Least Developed Countries (LDCs) - the most disadvantaged countries worldwide - however, the sustainability of the industry and its setting must be considered to ensure long term positive effects on community development and poverty alleviation.

This research looks at sustainable tourism as a tool for development in LDCs, in particular it focuses on Community Based Tourism (CBT) which, when well implemented, has emerged as an effective model to promote the development of sustainable tourism with benefits for all sectors of the community while protecting the longevity of the tourist product, and encouraging environmental and cultural conservation.

The practical implementation of sustainable tourism in LDCs via CBT models, however, faces many challenges. To understand these in a real world setting, Cambodia has been selected as it was identified as an LDC in 2001 and uses tourism as an 
economic development strategy with recent high-level attention being given to CBT.

Case studies of two rural communities in Cambodia - Banteay Chhmar, Banteay Meanchey Province, and Banlung, Ratanakiri Province - are used in this study to explore how CBT has been implemented to stimulate economic development at the local level. These communities were selected for this study because their reported outcomes were completely different and garnering insights from their CBT experience would ideally enhance knowledge of CBT in vulnerable LDC communities.

\section{Literature Review}

As a development tool to facilitate economic development, tourism is a non-heavy industry with relatively few barriers to entry (Weaver \& Lawton, 2002). In LDCs, a lack of money is a major cause of socio economic disadvantage, and many residents in LDCs live in poverty (Dao, 2004). Tourism is frequently seen as a quick and easy solution to economic disadvantage and, optimistically, it is assumed that increased wealth will resolve other social problems as economic benefits will trickle down to increase everyone’s standard of living (Gossling, 2003; Rogerson, 2007).

Rarely, however, does tourism income reach poorer community sectors as income leaks out of local communities to international or out of district domestic investors (Carbone, 2005; Stoeckl, 2007). Any remaining local funds are likely to go to the local elite rather than poorer residents (Feng, 2008; Rogerson, 2007).

Where governments lack the necessary frameworks, which is common in LDCs, rapid uncontrolled tourism development can occur to the detriment of communities (Akpabio, Eniang, \& Egwali, 2008; Hanh, 2006). While rapid tourism development produces short term economic benefits, the social and environmental costs quickly outweigh the benefits. Tourism must contribute to the community in a meaningful way to achieve long term success (Jayawardena, Patterson, Choi, \& Brain, 2008). 
The challenge for sustainable tourism as a development tool for LDC communities is the demand to achieve fast widespread benefits while still achieving long term industry sustainability (World Tourism Organisation, 2005). CBT, a model of sustainable tourism focused on community capacity building and the broad distribution of benefits, has been purported as a potential solution to this challenge (Gossling, 2003; Rogerson, 2007).

Though CBT is criticised for not being able to demonstrate clear socio-economic or conservation benefits due to its broad strokes approach to tourism development, the importance CBT places on community involvement and ultimately ownership recognises the role of community participation in establishing and maintaining sustainable tourism with greatest mutual benefit for hosts and guests. Indeed, community participation is considered vital for the successful development of tourism, particularly in smaller or more isolated community settings where impacts are more keenly felt by residents (Fahmi et al., 2013; Kibicho, 2003). Therefore, CBT is a more flexible framework for tourism development that is "strongly supported by international organisations, NGOs, governments, international development agencies and indigenous peoples” (Ruiz-Ballesteros \& Brondizio, 2013, p. 323) which has led to its popularity as an approach to tourism development in LDCs used by external implementers(Jayawardena, 2008; Ying \& Zhou, 2007) where sustainability and community development are priorities.

However, as LDCs are economically disadvantaged in the global context, internal and external issues associated with "power” are often problematic. Community participation, as an approach, is not always a reality in developing countries with “...formidable operational, structural and cultural limitations” (Tosun 1999, p. 113). 
For LDCs, the obstacles for community participation and perceived power imbalances usually means that CBT projects are initiated by an external group (government or NGO). In this scenario, there is a real risk that the community's lack of experience and dependence on external stakeholders for aid and support could exclude them from meaningful engagement in the critical initial planning stages and undermine their ability to assume ownership of tourism (Buccus, Hemson, Hicks, \& Piper, 2008; Manyara \& Jones, 2007). Without the community taking control of tourism after implementation, projects are at high risk of losing momentum and failing without the ongoing support of the implementers (Manyara \& Jones, 2007; Shunnaq, Schwab, \& Reid, 2008). The benefits tourism was supposed to provide to the community are then undeliverable, the relationship with the implementers damaged and community confidence shaken.

So while the motives of CBT are admirable and might appear easy to achieve on paper, the reality in the field is more challenging and complex. Indeed, in summary, Figure 1 presents an overview of the theoretical framework surrounding CBT implementation in LCDs where theoretical and practical challenges interplay to create some real challenges for CBT implementation including less effective models for implementation, less effective information for practitioners, power imbalances and conflicting goals for CBT.

Figure 1 Theoretical framework surrounding CBT implementation in LCDs

Overall there is a need to inform a model for best practice of CBT. To contribute to this, the research question for the overarching study was: "What is the role of the community in the successful implementation of CBT in LDCs?” This paper, however, solely focuses on the findings associated with resident perceptions of self, the 
community and tourism organisations. It considers the implications of community perceptions on project outcomes and their use as potential indicators for community pre-selection for CBT.

\section{Methodology}

Cambodia was selected for research into CBT in LDCs as it has a number of active initiatives and, importantly, the principle researcher also had unique tourism, cultural and language skills (as an Australian of Cambodian descent) enabling her to undertake this study in this little-researched setting.

A list of potential research sites were identified from the Cambodian Community Based Ecotourism Network's list of active CBT projects. The selection criteria for the case study sites selected were: they must have an established CBT project; the tourism must be based on an existing natural or cultural tourism asset; and the tourism project must have clearly defined community development goals. From the list of possible communities, Banteay Chhmar and Banlung were then selected because of their physical accessibility to the researcher during field work.

The study began in Banteay Chhmar in November 2009 with the researcher networking within the community and building rapport before undertaking in-depth semi-structured qualitative interviews with tourism committee members, participants in the tourism industry, and non-participating community members.

Initial scoping questions sought to find out how and why the CBT project had started, and the current experience of the project on the individual, their family and the broader community. The researcher guided the participant through a re-count of the CBT process and prompted them for more information as interesting points came up.

On return to Australia, the 22 interviews were transcribed by a translator recognised by Australia’s National Accreditation Authority for Translators and 
Interpreters (NAATI). Transcripts were then uploaded into NVivo software before the researcher undertook preliminary analysis by coding to identify emerging themes from the data. Based on initial findings, the original semi-structured interview questions were revised to enhance the accuracy and focus of data collection before returning to Cambodia to undertake the next case study in Banlung.

The researcher arrived in Banlung in March 2010. The same approach of purposive sampling continued to ensure a diverse cross section of informants from the tourism committee, tourism industry, and non-participating community members was achieved. The 26 interviews were then preliminarily translated and analysed in Cambodia. Emerging findings then led to a return visit to the first community, Banteay Chhmar, to address any gaps where an additional 19 follow-up interviews were conducted. This second visit occurred in late March 2010.

Altogether, the 67 interviews from both communities underwent thorough, iterative, thematic analysis to identify the overarching key themes presented in the findings. Resident perceptions emerged as a key theme across all interviewees and will be the focus of discussion in this article.

\section{Results}

On concluding analysis, what clearly appeared to be different between the two Cambodian communities where CBT had been implemented were resident perceptions of self, community and tourism organisations.

\section{The Banteay Chhmar Community}

Banteay Chhmar is a village in Banteay Meanchey Province, Cambodia, located approximately $40 \mathrm{~km}$ from the Thai border. It is an isolated, agrarian community, the primary industries being rice and cassava production. The main assets utilised for 
tourism are the ruins of the Banteay Chhmar temple in the centre of the village, built in the $12^{\text {th }}$ century, which is surrounded by many small satellite temples. The living culture products include oxcart rides, silk weaving and home stays. Figure 2 below is a map of Cambodia indicating the location of Banteay Chhmar.

Figure 2 Map locating case study sites in Cambodia.

\section{Perception of Self}

Residents of Banteay Chhmar perceive themselves as inferior to most other people they encounter. They feel uneducated, ignorant and isolated due to their experiences of Cambodian Civil war and its longer term effects:

I am ignorant of the outside world... I want my children to learn, to be educated. Do you know where poverty stems from? Ignorance. That is why we are poor. We are very poor. When I think about the past, I was so poor. My parents were so poor. I had one sibling, and my parents, they all died during Pol Pot times. (IBCJM09, Farmer, Banteay Chhmar)

The people in this community undervalue their own skills and experience. Disempowered, they look to people with apparent superiority - with money or power to do things for the community rather than generate solutions within:

I wish that the organisations in Siem Reap and Phnom Penh, when they hear this, they would help...If the community has a lot of partners, or if there is a tourist organisation in Phnom Penh, if they knew about this, they could bring some visitors to Banteay Chhmar. (IBCTM03, Homestay owner and farmer, Banteay Chhmar)

\section{Perceptions of Community}

In contrast to their lowly perception of self, residents of Banteay Chhmar were proud 
that their community has survived historically harsh conditions. Having an ancient temple proudly links the community to Angkorian times while its darker modern civil war history has unified the people through their experiences of survival. Community pride encourages people to work together to support larger goals, such as giving time from regular paid employment to help raise funds for larger community projects through tourism. This is evident in one resident's commitment to his community beyond any personal benefits he could achieve:

I will help the community all along. I will gain some income from it, and I will help the community so that the community will prosper. I want this community to develop further to gain income. (IBCJM01, Homestay owner and farmer, Banteay Chhmar)

With a community focus on the 'greater good', individuals are then more willing to volunteer to support tourism:

This is just an additional job to our occupation. It is not a priority job, or only for the livelihood of the group to do this... Our group has been working for a while now, we don't think about our salary or our remuneration or anything like that. The most important thing is our goals, so that our local area develops and progresses further. Before we can become developed, you have to make sacrifices, like time, to participate for the benefit of the community. (IBCJM02, Homestay owner and farmer, Banteay Chhmar)

Even residents with less overall involvement in tourism are willing to participate when called upon:

When there are visitors coming, and they need to go places, and the committee needs us to show them places, I help them out through the community. Sometimes I have the pagoda committee asking me to be involved in pagoda matters, so I help them once in a while. After that I return to work as usual...The committee works well because the members of the committee work very hard. .. I don't mind if it's 
night or day. I do what the committee needs me to do. (IBCMUM016, Activities group and farmer, Banteay Chhmar)

In Banteay Chhmar there is a general willingness to endure some personal sacrifice to achieve longer term community tourism goals. Major achievements so far, beyond activities to continue to grow tourism, is the provision of clean water for all residents and starting a waste management program for the village. These projects are funded by the revenue from tourism

This community solidarity has also encouraged an ease of communication which, in turn, has facilitated tourism-related educative workshops to identify community tourism aims, identify any risks and encourage support for tourism. This community's natural tendency to gossip about everything means that any information is spread through the entire community very quickly, without the need for much follow up or work on the part of the tourism committee, however, it also reinforces the more official channels:

\footnotetext{
We spread information by inviting the villagers to participate in our meetings...the invitations are for the four heads of the villages, and through the heads of the villages, they spread the information to the villagers in their respective villages....in the villages, they have groups. The village heads give out the information to the groups. Within the groups, there are subgroups as well...The head of the groups, because the villages aren't that big, will go to each house to tell them the information. (2IBCCOMM01, Treasurer, CBT Banteay Chhmar)
}

The success of communication may be due to the small size of the community, however, having a cohesive community does seem to encourage a well-established and effective communication network where people are genuinely interested in each other's business. In this case, it has facilitated CBT development. 
The way participants perceive the tourism committee in the community is a key factor to the success of CBT in Banteay Chhmar. It occupies a position of authority and the community's tourism goals are reflected in the actions of the committee. The transparency and trust it demonstrates encourages support for tourism.

This trust is the result of intensive work by the committee. It strives to be impartial and objective, and concerns itself only in tourism matters. It is clear that the tourism committee is not affiliated with any government agency, NGO, local government department or private enterprise. The tourism committee is made up of volunteers, so there is no potential for corruption through financial incentive: "I think that this community tourism project operates well because it is not under any organisation, political party or company's influence at all.” (IBCGHFM05, GHF Liaison, Banteay Chhmar)

This tourism committee is responsible for setting the tourism development goals to be funded by tourism. The goal setting is realistic, within the capabilities of the community, and is done with community participation. One committee member explains:

\footnotetext{
We are an independent committee which helps develop the local area and we operate on consensus. When we decide to spend money on a project, we call a committee meeting and when we get a majority decision, we access our funds and spend it on that project. We don't just make decisions based on a majority vote, no, we look at people's sentiments and facial expressions. Sometimes, if we have made a decision and have a majority greater than $51 \%$, but there is someone who disagrees very strongly, we have to facilitate that. (IBCGHFM05, GHF Liaison, Banteay Chhmar)
}

The committee has faith in itself and its people to achieve the goals that they have set. This empowers the committee to continue with their projects and encourage 
tourism development in the community: "I believe that our committee in Banteay Chhmar will succeed... The community also hopes that we will be able to stand on our own two feet into the future.” (2IBCCOMM01, Treasurer, CBT Banteay Chhmar)

\section{The Banlung Community}

Banlung is the provincial capital of Ratanakiri, Cambodia (see Figure 2). It is a small town near the Vietnamese border. Waterfalls and a volcanic lake are the primary natural tourism assets. The town is extremely isolated, and is home to a number of ethnic communities, who are living cultural tourism assets.

\section{Perceptions of Self}

The people of the community in Banlung, perceive themselves as disadvantaged, with a poor standard of living and education. One resident believes her lack of education and personal capabilities hold her back from participating in tourism:

If I was going to do it myself [create and maintain a tourism industry], I don't think I could, because I do not have the capabilities to make it work...If I could, I would like to be elected as a president, because I like this area and I am interested in tourism. But I don’t know foreign languages. (IBLF02, Resident, Banlung)

The poverty and isolation in Banlung has led to its people striving for survival above all else. Most individuals focus on securing their own immediate future and improving it with any opportunity they are given; regardless of whether the opportunities are legal, or have adverse impacts on the community, for example, poaching or cutting trees at protected tourism sites for charcoal production. This presents a major challenge for community support of CBT for long term success. As one frustrated resident explained: 
I would like this community to wake up. To do something for themselves. To help themselves. To develop things around their village to help themselves. To not think of themselves all the time. They should think of public benefits as well. They think that CBT doesn't benefit them, so every day, they go to collect cashew nuts instead, planting the fields, doing other things for themselves more than the community. (IKTM02, Resident, Katieng waterfall, Banlung)

Tourism is not a collective priority for Banlung. While the majority of people support the ideas and theoretical goals of CBT in their community, as individuals, their actions do not support CBT. This said, some were enthusiastic about participating in the tourism committee to enhance their opportunities because they do have faith in personally achieving a better life via their own hard work. One resident expressed hope for her future:

Personally, I would like to work in a tourist organisation... Sometimes I think I am not capable, but it’s alright, I think. I think I will only do this temporarily. When another job comes, I will try and do my best. (IBLF02, Resident, Banlung)

While the residents of Banlung have a strong work ethic that would support CBT, a lack of collaboration means that benefits are not shared across the community. Years of isolation and experiences during the war have resulted in a deep mistrust between community members and, in particular, of government authority. As government has been a key driver of tourism development in Banlung to date, CBT has been undermined by distrust. For example, the tourism committee members showed actual fear answering questions about government for this study:

You are going to write about tourism just to increase awareness, so other people can read and know about it? There is no problem then. But if I start talking about anything to do with politics, I do not want to touch that area. (IBLTCM01, Secretary CBT, Banlung) 
People in the community refuse to express their own opinions to avoid potential conflict:

I don't think people can do anything, because people are afraid of authority. When important people come, they seem to be afraid of them. Even me, I am just a guide, a normal person. I haven’t got a rank or anything...they are even afraid of me. (IBLTCM01, Secretary CBT, Banlung)

CBT cannot exist in this environment where individuals fear sharing their opinions, do not engage in long-term planning and see personal gain as the only motivation for tourism development.

\section{Perceptions of Community}

There are diverse ethnic groups within the Banlung community dividing it along cultural lines. This presents a challenge for open communication within the community. The tourism committee secretary hints at the difficulties this ethnic divide presents:

[The ethnic people] can communicate between themselves using their own language. So they select the people who can read and write the language as workers in the community. (IBLTCM01, Secretary CBT, Banlung)

These groups also attract more aid from NGOs than the wider community. Different ethnic groups have been singled out by external agencies for tourism awareness programs designed to prevent negative social and cultural impacts of tourism:

At the community level, there are organisations who come and teach them about the negative impacts of tourism. They try to prevent the bad things from happening first, because tourism can bring in drugs... In relation to drugs sometimes people or organisations take sweets to the villages...the visitors took some cakes and sweets to the village, and some books. As for the cakes, they didn't want to accept it, and the reason we were told was that they were afraid that they could be drugs, they 
were told by an organisation who was teaching them that tourists could bring drugs. (IBLTCM01, Secretary CBT, Banlung)

Many ethnic groups have developed a fear of tourism because they worry about the negative impacts they have been warned of. This discourages participation in CBT and cooperation between the community groups.

So division in the community, together with its larger size, makes free-flowing communication within the community extremely difficult. There is a general distrust of authority and a fear of expressing a personal opinion. Moreover, people are less interested in the everyday activities of the community, as they are more focused on their own individual wellbeing.

As a whole, the community does not see tourism as a common priority. Its lack of unity, and no sense of 'greater good', means that there are too few people to be champions for CBT. One resident was frustrated by this:

The tourism authority has a lot of conservation in mind, but this community is very lazy. They can't help themselves... The community doesn't do anything much towards tourism. The tourism office provided all the signs in the area, not the community... They would like the villagers to come and participate in selling tickets to tourists, to collect the fees, so that the proceeds can be used in the village itself. But the villagers in the community don't want to come and do it. Like today, I have not seen them come, it's been four days now. (IKTM02, Resident, Katieng waterfall, Banlung)

CBT is therefore not being successfully achieved in Banlung because there is no community buy-in.

\section{Perceptions of the Tourism Organisation}

The committee in Banlung meets irregularly, and has no formal plan - this responsibility is left to the tourism office. There is little commitment to develop CBT - they are 
reluctant to control tourism development.

Tourism provides employment for committee members, as freelance guides. They perceive they have limited powers, no support and little financial gain from their involvement; their activities are limited and committee members give priority to other aspects of their lives:

In our association, we have a president, two vice presidents, a secretary and a treasurer. Five of us, but there are no members...We had a meeting and a constitution was written and an election was held...I voted as well, but I didn't stand for president, because I haven't got many resources and I have to support myself ....If I had a good livelihood, I could stand for president. My wife could have a business and I could work for the association, organising and planning and making projects...Even the president doesn't do much. If he has guests, he still takes them around, but if he has no guests, he organises soccer games to earn money. (IBLTCM01, Secretary CBT, Banlung)

Without a commitment to CBT, the committee has not had any significant achievements. The tourism organisation is therefore poorly perceived.

In Banlung, many ethnic groups have their own site-based tourism attraction committees which are part of the larger community structure with an appointed leader. With each community having a different leader, who is generally not involved in tourism, there is no co-operation or communication between the individual communities or committees regarding CBT. Therefore, without the tourism committee operating effectively, there is no one taking responsibility for CBT in the wider Banlung community.

\section{The role of resident perceptions in $\mathrm{CBT}$}

In LDCs, resident perceptions of self are often negative and disempowering (Suntikul, Bauer, \& Song, 2010) and while this was the case in the two communities, in Banteay 
Chhmar a positive perception of community helped to overcome this. Indeed, according to Galea et al. (2010) and Lever, Pinol, \& Uralde (2005), strong internal relationships build a positive perception of community which can overcome even the psychological effects of poverty and war which appears to be the case in Banteay Chhmar.

Feeling good about your community builds trust which, in turn, encourages a positive attitude towards local tourism organisations. In Banteay Chhmar it was evident that the tourism committee was positively viewed. This trust is a key to success in political and economic environments that are typically threatened by corruption (Widner \& Mundt, 1998).

Once empowered by community support, the Banteay Chhmar tourism committee could actively pursue CBT development goals. The increasing success of the CBT, and its widely distributed benefits, then continued to improve resident perceptions of the committee. This then garnered further local support for tourism, as evidenced by a growing commitment to tourism-related volunteerism. Huang and Hsu (2011) note that volunteers and their community organisations are a key to development with the social networks creating cohesive communities. Tosun (1999) suggests that volunteerism is an indicator for spontaneous participation - the most ideal type of community participation - as "spontaneous participation is voluntary, base-up without external support” (p. 118).

In Banlung, in contrast, resident perceptions of community were poor and there was a strong focus on individual needs. In this scenario the tourism committee was barely functional, though some attraction-based committees - usually run by a specific ethnic group- were somewhat more successful, perhaps due to trust and coordination at this sub-cultural level. This said, no one could represent Banlung with regards to tourism. 
In Banteay Chhmar, the positive perceptions and trust placed in the community facilitated the support of CBT and the growth of contributions by residents despite individuals lacking the confidence themselves. In Banlung, though there is in-principal support for CBT, the lack of trust in both themselves and the community means there was little active support or contributions by residents to progress the practical implementation CBT to a point where it can be self-sustaining. In this case, positive perception of community has overcome the impact of negative perception of self on the successful development of CBT.

Communication plays an important role in the development of positive perceptions of community. Binns and Nel (2002) noted that the existence of good communication pathways in a community is indicative of strong interest in community issues. Communication is also central for CBT, as both official and unofficial communication channels can be used to increase awareness of CBT in the community. Good community awareness and understanding of CBT then establishes a foundation for local support and participation, thus enhancing potential for a successful project outcome (Hall, 2000).

In Banteay Chhmar information flowed freely about CBT. People knew what was going on and were actively participating. This community had strong established networks based on its agricultural practice of collaborative harvest and sharing of which the tourism committee has taken advantage. While a tradition of collaboration in the community will not necessarily predicate cooperation in regard to the implementation of CBT (Mason \& Beard, 2008), open communication builds awareness of tourism (Aas, Ladkin, \& Fletcher, 2005) and through the nature of 'gossip’, residents inadvertently participate in CBT (Binns \& Nel, 2002). 
In Banlung, the contrary was seen as communication was stilted across different language and cultural divides. Such internal conflict decreases participation and damages communication pathways critical for the development of awareness of CBT (Ostwald, 2009), particularly the incidental participation in CBT through unofficial communication networks that can influence non-participants and increase support. There had been many NGO interventions yet the community still had no common understanding of tourism and there was little active participation. Only those who had a vested interested in achieving personal outcomes were keen, however they were still heavily reliant on external stakeholders to operate tourism. This reliance perpetuates the power imbalance and fear of authority which undermines the perception of community and potentially, according to Tosun (1999) community participation. Without community support, CBT could not escape this cycle and become independently responsible for CBT.

Community participation must be included from initial planning stages to ensure that the community's role in CBT is sufficient to empower them to assume control (Carbone, 2005; Kelly \& Moles, 2000; Mbaiwa, 2004; Muhanna, 2007). Based on Tosun's (1999) simplified typology of community participation, there is evidence of only passive or indirect participation in Banlung rather than the spontaneous participation evident in Banteay Chhmar.

The findings suggest that community control is more likely and effective where there is community cohesion. It encouraged communication thereby facilitating education and awareness. It promoted trust, pride and collaborative relationships. Where community cohesion was present, the benefits of CBT were experienced by more residents. 


\section{Conclusion}

While appropriately implemented CBT can generate community benefits and a sustainable, long-term, local tourism industry this research found that a community's dynamics might affect the overall outcomes. Moreover, with further refinement, resident perceptions might be able to be considered an indicator that can be taken into account prior to embarking on a CBT project - particularly if several communities are being considered, resources are limited and a choice on which communities to include or exclude has to be made.

This study, albeit based on these two Cambodian communities, suggests that

CBT is best achieved in a cohesive community where trust encourages open communication. Informed residents are then more likely to collaborate and engage in the establishment and operation of CBT. It is proposed that consideration of resident perceptions of self and community may be useful to practitioners prior to embarking on a CBT project. While further empirical examination is required, the figure below highlights the theoretical role of resident perceptions on CBT outcomes in LDCs.

Figure 3 A theoretical model of the role of resident perceptions in potentially influencing CBT project outcomes

In this model, resident perceptions of self and community play a major part in the successful implementation of CBT. An understanding of these influences may help to overcome practical challenges during implementation and transition to independent community management, identifying potential 'red flags', but also providing a balanced perspective of their true impact on a project. For example, though negative perceptions of self may be seen as a 'red flag', in the case of Banteay Chhmar, it is revealed that the positive perception of community effectively ameliorates this. The mix of perceptions 
of self, community and the tourism organisation combined affect the way CBT is embraced in a community, and therefore how implementers should adjust their approach.

While this qualitative explorative study elucidated this, further research could explore ways of assessing a community’s communication networks and cohesiveness to enable NGOs to identify and target CBT-ready communities or allocate additional resources for preparing communities for CBT, which would assist project planning in increasingly difficult operating environments. Alternatively, taking an optimistic approach, a future study could be undertaken where community cohesion is weak with a view to see if engagement in the CBT process might actually bolster cohesion overtime. Indeed creating an effective tourism committee - with people who appear to be willing to go above and beyond for the common good - does appear to have been a factor in successful CBT for Banteay Chhmar and offers some possibilities for successful CBT implementation in currently less cohesive communities.

\section{Implications}

Understanding community dynamics through an investigation of resident perceptions of self and community could facilitate the selection of communities more likely to achieve successful implementation of CBT in LDC communities or highlight areas where implementers must invest additional resources in developing trust, cohesion and communication networks to promote long term success.

\section{References}

Aas, C., Ladkin, A., \& Fletcher, J. (2005). Stakeholder Collaboration and Heritage Management. Annals of Tourism Research, 32(1), 28-48. 
Akpabio, I. A., Eniang, E. A., \& Egwali, E. C. (2008). Socio-economic potentials and environmental implications of coastal tourism at Adiabo, Cross River State, Nigeria. Environment, Development and Sustainability, 10(3), 249.

Binns, T., \& Nel, E. (2002). Tourism as a Local Development Strategy in South Africa. The Geographical Journal, 168(3), 235-247.

Buccus, I., Hemson, D., Hicks, J., \& Piper, L. (2008). Community Development and Engagement with Local Governance in South Africa. Community Development Journal, 43(3), 297-311.

Carbone, M. (2005). Sustainable Tourism in Developing Countries: Poverty Alleviation, participatory planning, and ethical issues. The European Journal of Development Research, 17(3), 559-565.

Dao, M. Q. (2004). Rural poverty in developing countries: an empirical analysis. Journal of Economic Studies, 31(6), 500-508.

Fahmi, Z., Hamzah, A., Muhammad, M., Yassin, S.M., Samah, B.A., D’Sika, J.L. \& Shaffril, H.A.M. (2013). Involvement in Agro-Tourism Activities among Communities in Desa Wawasan Nelayan Villages on the East Coast of Malaysia. Asian Social Science, 9(2), 203-209.

Feng, X. (2008). Who Benefits?: Tourism Development in Fenghuang County, China. Human Organization, 67(2), 207.

Galea, S., Rockers, P. C., Saydee, G., Macauley, R., Varpilah, S. T., \& Kruk, M. E. (2010). Persistent Psychopathology in the Wake of Civil War: Long-term posttraumatic stress disorder in Nimba County, Liberia. American Journal of Public Health, 100(9), 1745-1751.

Gossling, S. (2003). Market Integration and Ecosystem Degradation: Is sustainable tourism development in rural communities a contradiction in terms? Environment, Development and Sustainability, 5(3-4), 383.

Hall, D.R. (2000). Tourism as sustainable development? The Albanian experience of 'transition'. International Journal of Tourism Research, 2(1), 31-46.

Hanh, V. T. H. (2006). Canal-side highway in Ho Chi Minh City (HCMC), Vietnam: Issues of urban cultural conservation and tourism development. GeoJournal, 66(3), 165.

Huang, L.-L., \& Hsu, J.-Y. (2011). From Cultural Building, Economic Revitalization to Local Partnership? The changing nature of community mobilization in Taiwan. International Planning Studies, 16(2), 131-150. 
Jayawardena, C., Patterson, D. J., Choi, C., \& Brain, R. (2008). Sustainable Tourism Development in Niagara. International Journal of Contemporary Hospitality Management, 20(3), 258-277.

Kelly, R., \& Moles, R. (2000). Towards Sustainable Development in the Mid-West Region of Ireland. Environmental Management and Health, 11(5), 422-432.

Kibicho, W. (2004). Community Tourism: A lesson from Kenya’s coastal region. Journal of Vacation Marketing, 10(1), 33-42.

Lever, J. P., Pinol, N. L., \& Uralde, J. H. (2005). Poverty, Psychological Resources and Subjective Well Being. Social Indicators Research, 73(3), 375-408.

Manyara, G., \& Jones, E. (2007). Community-based Tourism Enterprise Development in Kenya: An exploration of their potential as avenues of poverty reduction. Journal of Sustainable Tourism, 15(6), 628-644.

Mason, D. R., \& Beard, V. A. (2008). Community-Based Planning and Poverty Alleviation in Oaxaca, Mexico. Journal of Planning Education and Research, 27(3), 245-260.

Mbaiwa, J. E. (2004). Prospects of Basket Production in Promoting Sustainable Rural Livelihoods in the Okavango Delta, Botswana. The International Journal of Tourism Research, 6(4), 221-235.

Muhanna, E. (2007). Tourism Development Strategies and poverty elimination. Problems and Perspectives in Management, 5(1), 37.

Ostwald, C. H. (2009). A Deeper Look at Poverty: Challenges for Evangelical Development Workers. Transformation: An International Journal of Holistic Mission Studies, 26(2), 130-145.

Rogerson, C. M. (2007). Tourism Routes as Vehicles for Local Economic Development in South Africa: The example of the Magaliesberg Meander. Urban Forum, 18(2).

Ruiz-Ballesteros, E. \& Brondizio, E.S. (2013). Building Negotiated Agreement: The emergence of community-based tourism in Floreana (Galapagos Islands). Human Organization, 72(4), 323-336.

Shunnaq, M., Schwab, W. A., \& Reid, M. F. (2008). Community Development Using a Sustainable Tourism Strategy: A case study of the Jordan River Valley touristway. The International Journal of Tourism Research, 10(1), 1. 
Stoeckl, N. (2007). Regional expenditure patters, remoteness and type of enterprise: Which tourism businesses spend the largest amount within their local communities? Economic Papers - Economic Society of Australia, 26(1), 64.

Suntikul, W., Bauer, T., \& Song, H. (2010). Towards Tourism: a Laotian perspective. International Journal of Tourism Research, 12(5), 449-461.

Tosun, C. (1999). Towards a typology of community participation in the tourism development process. Anatolia, 10(2), 113 - 134.

Weaver, D., \& Lawton, L. (2002). Tourism Management (2nd ed.). Milton: John Wiley and Sons.

Widner, J., \& Mundt, A. (1998). Researching Social Capital in Africa. Africa, 68(1), 124.

World Tourism Organisation. (2005). Indicators of Sustainable Development for Tourism Destinations: A guidebook. Madrid, Spain: World Tourism Organisation.

Ying, T., \& Zhou, Y. (2007). Community Governments and External Capitals in China's Rural Cultural Tourism: A comparative study of two adjacent villages. Tourism Management, 28(1), 96-107. 
Figure 1 Theoretical framework surrounding CBT implementation in LCDs Overall there is a need to inform a model for best practice of CBT.

Figure 2 Map locating case study sites in Cambodia.

Figure 3 Role of resident perceptions in CBT implementation 